\title{
The Morphometric study of the normal and variant branching pattern of the Aortic arch by cadaveric dissection
}

\author{
Junagade $\mathbf{B}^{1}$, Mukherjee $\mathbf{A}^{2}$ \\ ${ }^{1}$ Dr. Bhavana Junagade, Assistant Professor, Department of Anatomy, MGM Medical College, Kamothe, Navi Mumbai, \\ ${ }^{2}$ Dr. Aruna Mukherjee, Professor and HOD, Department of Anatomy, MGM Medical College, Kamothe, Navi Mumbai
}

Address for correspondence: Dr Bhavana Junagade, Email: bhavanajunagade@ yahoo.co.in

\begin{abstract}
Introduction: A thorough knowledge of the anatomy of the arch of aorta and its branches is of great importance today as the arch is assuming a key role in many endovascular surgeries. The varying configuration of the arch and its branching pattern are one of the main risk predictors in many endovascular surgeries such as carotid artery stenting. Methods: In the present study, the morphology and the morphometry of the aortic arch and its branches has been studied on 35 embalmed human cadavers. Results: The arch showed variant branching pattern in $11.43 \%$ cadavers. In variations, the arch was found to give rise to only 2 branches in 3 cadavers and 4 branches in 1 cadaver as against normal pattern of 3 branches. The brachiocephalic trunk, the left common carotid artery and the left subclavian artery had mean outer and inner diameters as $13.22 \mathrm{~mm}$ and $10.8 \mathrm{~mm}, 8.06 \mathrm{~mm}$ and $6 \mathrm{~mm}$ and $9.95 \mathrm{~mm}$ and $8.38 \mathrm{~mm}$ respectively. In $28.5 \%$ specimens the brachiocephalic trunk originated on the left of the mid-vertebral plane. Conclusion: The arch morphology is variable and becomes more so with the advancing age. Advanced non invasive radiological angiographic procedures such as, 3 dimensional CT scan or MRI have limitations in understanding actual three dimensional structure of these vessels. Thus in this era of increasing vascular invasive procedures the knowledge gained from this study will be useful to the cardiologists, cardiothoracic surgeons and radiologists in various diagnostic and therapeutic procedures, to manipulate within these vessels.
\end{abstract}

Key words: Aortic Arch, Branching Pattern, Vertebral Artery

\section{Introduction}

The configuration of the arch of aorta and its branching pattern is assuming a key role in many endovascular surgeries, like carotid artery stenting, due to their role as one of the main risk predictors.

The varying configuration and morphometry of the arch and its branches is a result of their complicated development from the right and left horns of the aortic sac and first five branchial arch arteries.

Clinically significant variations occur in almost $35 \%$ of the population [1]. A detailed study of the morphometry of the arch of aorta is thus imperative for the cardiothoracic surgeons to avoid surgical complications. The knowledge of the morphometry of these arteries, normal and variant, is important for manipulation within these vessels and also in preoperative selection

Manuscript received: $23^{\text {rd }}$ May 2015

Reviewed: $4^{\text {th }}$ June 2015

Author Corrected: $14^{\text {th }}$ May 2015

Accepted for Publication: $5^{\text {th }}$ June 2015 of the catheters and instruments.

Advanced non invasive radiological angiographic procedures such as, 3 dimensional computerized tomographic (3DCT) scan or magnetic resonance imaging (MRI) have limitations in understanding actual three dimensional structure of these vessels needed for the catheter rmanipulation or the instrument negotiation [2].

Some of the variant branching patterns of the arch assume more clinical relevance. Such as left vertebral artery when arises as a variation directly from the arch (up to $5 \%$ ) poses a problem in preoperative diagnosis with available radiological techniques, due to its smaller size which gets overshadowed by the other larger branches of the arch [3].

Studying branches of the arch with respect to the morphometry and variations helps in understanding the 
cerebral hemodynamics and the cerebral abnormalities [4].

\section{Material and Method}

The study has been conducted in the department of Anatomy, Mahatma Gandhi Mission Medical College, Kamothe, Navi Mumbai, on 35 embalmed adult human cadavers. All the dissected cadavers were in the age group of 50 to 70 years. The cadavers with any surgery done in the area to be dissected were excluded from the study.

The dissection was done as per Cunningham's manual of practical anatomy volume 2 [5] and volume 3 [6]. For the dissection of the superior mediastinum the manubrium sterni was cut transversely below the $1^{\text {st }}$ chondrosternal joint. The ribs were cut in the anterior axillary line and the anterior wall of the rib cage turned downwards.

The clavicles were cut at the junction of the medial and middle $1 / 3^{\text {rd }}$ and the manubrium reflected upwards. The aortic arch and its branches were dissected and cleaned as per Grant's dissector [7].

The branches of the arch were further traced in the neck by dissecting in the carotid and the supraclavicular triangles. [6] The common carotid artery was traced till its bifurcation in to internal and external carotid arteries. The subclavian artery was traced till the outer border of the first rib.

After observing the branching pattern of the arch the following parameters were studied,

\section{The lengths of}

- The brachiocephalic trunk (BCT)

- The left common carotid artery (LCCA)

- The left subclavian artery ( from origin to the outer border of the first rib) (LScA)

The outer and the inner diameters of the arteries were measured using the digital vernier calipers with the least count of $0.01 \mathrm{~mm}$.

The outer diameters were measured for

- Beginning of the arch (at the level of the second chondrosternal joint)

- End of the arch (at the level of the fourth thoracic vertebra)

The length and diameters

The length and inner and outer diameters were as depicted in the table 1.
- The brachiocephalic trunk (at origin)

- The left common carotid artery (at origin)

- The left subclavian artery (at origin)

The arch of aorta was cut and the inner diameters were measured for, BCT, LCCA and LScA. Presence or absence of ridges near the inner openings was observed.

Angles: Angles were measured with the goniometer.

Angle between the arch and its major branches : The angles were measured between the left side of each branch at its origin and the arch of aorta. Angles were measured for the BCT, LCCA, LScA and any variant branches.

Also the origin of BCT, to the left or right, with respect to Mid Vertebral Plane (MVP), was observed and its distance from MVP was measured. The variations in the branching pattern of the arch were observed. Appropriate measurements were taken. The observations were then statistically arranged, analyzed using Microsoft excel 2010 and interpreted.

\section{Results and Observations}

In $31(88.57 \%)$ cadavers, the arch had abnormal branching pattern, that is, three branches, BCT, LCCA and LScA, from right to left.

In $4(11.43 \%)$ cadavers a variation in the branching pattern was noticed. In $3(8.58 \%)$ cadavers arch was having only two branches. BCT and LCCA were arising as a common trunk (CT) from the arch, with LScA as the second branch, to the left of the common trunk. While in $1(2.85 \%)$ cadaver, 4 branches were arising from the arch. From right to left these were - BCT, LCCA, left vertebral artery (LVA) and the LScA. The additional branch was confirmed as LVA by dissecting it, till its entry in the foramen transversarium.

\section{Diameters of the arch of aorta}

- The mean outer diameter of the arch of aorta at its origin was $26.44 \mathrm{~mm} \pm 4.61$.

- The mean outer diameter of the arch at its termination was $19.22 \mathrm{~mm} \pm 3.43$.

For the BCT, LCCA \& LscA 
Table 1: Showing length and diameters of BCT, LCCA and LScA

\begin{tabular}{|l|l|l|l|l|l|}
\hline \multirow{3}{*}{$\mathbf{1}$} & & & \\
\hline & \multirow{3}{*}{ Length $(\mathrm{cm})$} & BCT & $04.11 \mathrm{~cm}$ & \pm 0.60 & $3.1-5.5$ \\
\cline { 3 - 6 } & & LCCA & $11.40 \mathrm{~cm}$ & \pm 1.15 & $9.2-14.5$ \\
\cline { 3 - 6 } $\mathbf{2}$ & \multirow{3}{*}{ Inner diameter(mm) } & LScA & $07.70 \mathrm{~cm}$ & \pm 0.93 & $5.9-9.4$ \\
\hline \multirow{3}{*}{$\mathbf{3}$} & \multirow{3}{*}{ Outer diameter(mm) } & LCCA & $06.55 \mathrm{~mm}$ & \pm 1.55 & $7.8-17.2$ \\
\cline { 3 - 6 } & & LScA & $08.38 \mathrm{~mm}$ & \pm 1.61 & $3.11-11.12$ \\
\hline & & BCT & $13.22 \mathrm{~mm}$ & \pm 2.25 & $6.12-12.69$ \\
\cline { 3 - 6 } & & LCCA & $08.06 \mathrm{~mm}$ & \pm 1.44 & $10.12-19.4$ \\
\cline { 3 - 6 } & & LScA & $09.96 \mathrm{~mm}$ & \pm 1.72 & $6.15-12.4$ \\
\hline
\end{tabular}

Length of LScA till its $\mathbf{1}^{\text {st }}$ branch : LScA had the mean length of $3.24 \mathrm{~cm} \pm 0.79$ till the origin of its first branch, LVA. In all the specimens the length of this part of the LScA ranged from $2.1-4.3 \mathrm{~cm}$. But in one cadaver the LVA arose very close to the origin of the LScA from the arch. The length of LScA in this specimen till the origin of LVA, was just 6 mm.

Angles: The angles made by each branch with the arch at its origin were as depicted in the table 2.

Table 2: Showing angle made by each branch with the arch

\begin{tabular}{|l|l|l|l|l|}
\hline & & & & \\
\hline $\mathbf{1}$ & BCT & $88.09^{\circ}$ & 15.75 & $61-111$ \\
\hline $\mathbf{2}$ & LCCA & $46.21^{\circ}$ & 12.29 & $24-75$ \\
\hline $\mathbf{3}$ & LScA & $50.88^{\circ}$ & 14.17 & $26-82$ \\
\hline
\end{tabular}

Distance from the MVP For BCT

The table 3 shows relation of BCT with the mid-vertebral plane (MVP).

Table 3: Showing mean distance between BCT and MVP

\begin{tabular}{|l|l|l|l|l|l|}
\hline & \multicolumn{2}{|l|}{} & & & \\
\hline $\mathbf{1}$ & $\begin{array}{l}\text { BCT } \\
\text { MVP }\end{array}$ & $\begin{array}{l}\text { Origin on right of } \\
\text { MVP }\end{array}$ & 06 & 3.42 & $2-14$ \\
\cline { 2 - 6 } & $\begin{array}{l}\text { Origin on left of } \\
\text { MVP }\end{array}$ & 04.3 & 2.71 & $1-10$ \\
\hline
\end{tabular}

The BCT originated on the left of the MVP in $10(28.5 \%)$ specimens with a mean distance of $4.3 \mathrm{~mm} \pm 2.71$ and a range of $1-10 \mathrm{~mm}$. While in 2(5.7\%) specimens it originated on the MVP. In rest of the specimens BCT originated on the right of the MVP.

The ridges formed by fibrous tissues were found to be present between the origins of the BCT and the LCCA in 18 $(51.4 \%)$ cadavers and between the LCCA and the LScA origins in only 7(20\%) cadavers.

\section{The variations}

Morphometry of the variations 


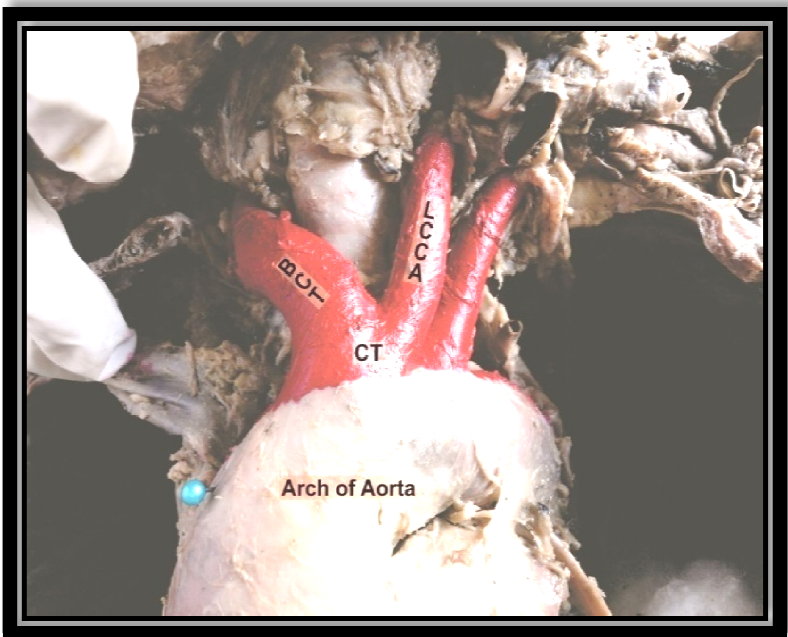

Figure1: Photograph: Origin of the common trunk from the arch

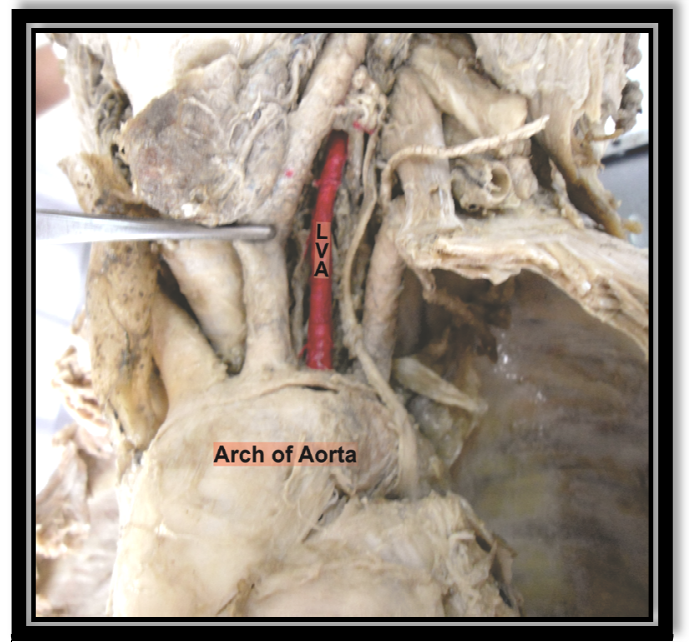

Figure 2: Photograph: Origin of LVA from the arch

The common trunk - 3(8.58\%) cadavers were found to have origin of the BCT and the LCCA from a common trunk (CT) arising from the arch of aorta. One of the specimens with CT is shown in figure1.

The CT showed mean length of $9.33 \mathrm{~mm}$ with a range of $(8-10 \mathrm{~mm})$. It arose at a mean angle of $64^{\circ}$ (on its left side) from the arch with a range of $\left(54^{\circ}-72^{\circ}\right)$. It always originated on the left of the MVP at a mean distance of $6.66 \mathrm{~mm}$ with a range of 5-10 mm. CT had mean inner diameter of $16.85 \mathrm{~mm}(14.35-20.41)$ and mean outer diameter of $18.39 \mathrm{~mm}(16.94-$ 21.27).

The mean distance at which CT took origin from the beginning of the arch was $26 \mathrm{~mm}(10-36 \mathrm{~mm})$.

Out of 35 cadavers $1(2.85 \%)$ specimen showed 4 branches arising from the arch. The artery arising from the arch between the origins of the LCCA and LScA was left vertebral artery directly taking origin from the arch, as seen in figure 2. LVA ( $1^{\text {st }}$ part) had the length of $8 \mathrm{~cm}$. It had outer diameter of $5.03 \mathrm{~mm}$ and inner diameter of $4.44 \mathrm{~mm}$.

\section{Discussion}

Thorough knowledge of the arch of aorta, its normal and variant branching pattern and morphometry is of utmost importance to the radiologists and cardiovascular surgeons to avoid accidental injury to any of these important vessels during surgery [8].

The arch of aorta branching pattern: The development of the arch and its branches from multiple sources forms a basis for increased number of chances of variations in the population.

According to Shivkumar et al, variant branching pattern can alter cerebral hemodynamics leading to cerebral abnormalities. The knowledge of these variations is important in the diagnosis of the intra cranial aneurysm after subarachnoid hemorrhage. In aortic arch surgeries these anomalies should be predetected. For example, ligation of the common carotid artery (CCA) can compromise posterior cranial fossa blood supply if anomalous vertebral artery is originating from the CCA [4].

According to the literature normal pattern is present in $65 \%$ of the population. [1,9]. The present study has found normal branching pattern in 31 cadavers that is $(88.57 \%)$ as seen in the following chart (fig. 3$)$. 


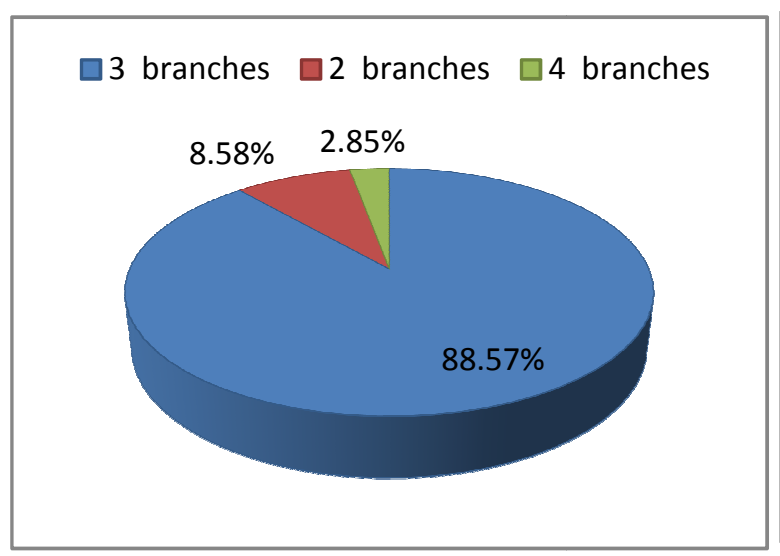

Fig 3: Chart for branching pattern of the arch

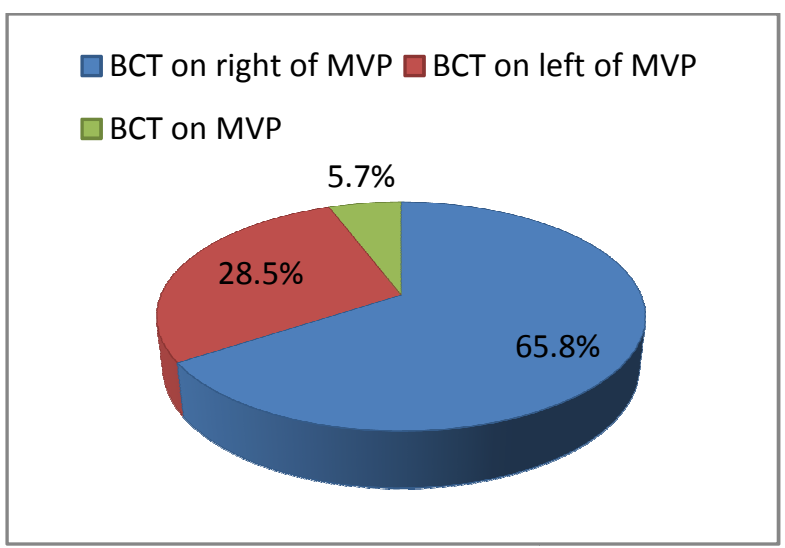

Fig 4: Chart for deviation of the BCT from the MVP
Shin and associates have reported a similar pattern with normal branching seen in $84 \%$ of the cases. [2]. Haifa A. reports normal pattern in $75 \%$ of the cases [10], while Adachi has shown it to be present in $80 \%$ of the cases. [11]. Anson and McVay has found it in $64.9 \%$ [12] and Ogengo J A in $67.3 \%$ [13]. One study by Rekha P. reports normal pattern in $92.72 \%$ of the hearts [14].

The present study has not taken into consideration any differences according to age, race or sex variations. Williams and Edmonds have found difference in percentage of variation in white and black race. They found that $39.8 \%$ blacks showed variant pattern while it was variant in only $21.4 \%$ whites [15].

Indumathi S. in her study reports normal branching pattern in $89.1 \%$ males and in $88.8 \%$ females. This shows that variations in males and females are comparable and there is not much sex variation [16].

In a study by Faggioli, $88.3 \%$ had normal branching pattern. He found common trunk for BCT and LCCA in $10.2 \%$ cases. He has reported that in Carotid artery stenting (CAS) procedures technical failure and neurological complications rate was higher in arch anomaly group. [17]

There are also rare but interesting anomalous branching patterns reported in the literature. One such pattern is reported by Dominic Wiedemann in which he found no BCT, LCCA as a branch of the ascending aorta, RCCA as the first and RScA as the second branch arising from the arch and LScA as a branch of the descending aorta [18].
The availability of the advanced non-invasive diagnostic procedures like angiography done by 3 dimensional computerized tomography or magnetic resonance imaging technique cannot replace knowledge acquired by direct cadaveric dissection. These radiological techniques have their own limitations in understanding actual three dimensional structure needed for catheter manipulation [2].

Also in the cases of cerebral aneurysms, 3DCT is able to show aneurysms of only $>5 \mathrm{~mm}$ diameters. Thus any patient with smaller aneurysm may still have to undergo invasive conventional cerebral angiography [19].

Diameter of the arch: Present study has found the outer diameters of the arch at its origin and termination to be respectively $26.44 \mathrm{~mm} \pm 4.61$ and $19.22 \mathrm{~mm} \pm$ 3.43 , which is similar to figures (28 mm and $20 \mathrm{~mm})$ quoted in the literature [9].

\section{BCT, LCCA, LScA}

Lengths: Present study has found the mean lengths of the major branches to be following,

- $\quad$ BCT -- $4.11 \mathrm{~cm} \pm 0.6(3.1-5.5)$

- $\quad$ LCCA -- $11.4 \mathrm{~cm} \pm 1.15(9.2-14.5)$

- $\quad$ LScA -- $7.7 \mathrm{~cm} \pm 0.93$ (5.9-9.4)

According to the Gray's anatomy the BCT is about $4-5$ cm in length [9].

Shin study has reported the mean length of the BCT to be $3.25 \mathrm{~cm}$. This length is slightly on the lower side compared to the findings of the present study and also the literature reports. [2] The length of the BCT can be a guide for the expected distance at which the origin of the RCCA can be found during catheter manipulation. 
The mean length of the LScA up to its first branch was found to be $3.24 \mathrm{~cm} \pm 0.79$. The first branch of the LScA in all the specimens was LVA except in one where LVA was a direct branch of the arch. Even though the length ranged from $0.6-4.3 \mathrm{~cm}$ it was actually in only one specimen that the length was found to be $0.6 \mathrm{~cm}$ and the range was otherwise $2.1-4.3 \mathrm{~cm}$.

Shin study states that for cerebral angiography of the posterior or vertebral circulation system LVA is generally chosen. The length of the LScA to LVA thus becomes important. They have reported mean length of the LScA till LVA to be $3.38 \mathrm{~cm}$ [2]. This finding is comparable to that of the present study.

Diameters: Mean outer diameters of the BCT, LCCA and LScA were found to be $13.22 \mathrm{~mm}, 8.06 \mathrm{~mm}$ and $9.95 \mathrm{~mm}$ respectively. Mean inner diameters of the BCT, LCCA and LScA were found to be $10.8 \mathrm{~mm}$, $6.0 \mathrm{~mm}$ and $8.38 \mathrm{~mm}$ respectively.

According to Shin the mean inner diameters of the BCT, LCCA and LScA were $18.3( \pm 7), 9.5( \pm 1.9)$ and 10.6( \pm 2.4$) \mathrm{mm}$ respectively [2]. According to Alsaif the mean inner diameters of the BCT, LCCA and LScA were $17.97( \pm 3.85), 9.77( \pm 1.9)$ and $14.33( \pm 3.09) \mathrm{mm}$ respectively [10].

In endovascular surgeries with the need for catheterization and instrumentation of these major branches, knowledge of their inner diameters is very important. This would help in selection of size of catheter and instruments. In all the studies BCT was the largest while LCCA was the smallest branch of the arch.

The inner diameters of the present study are significantly on the lower side as compared to the Shin study. The difference noted in two studies could be as a result of difference in the origin of two selected populations.

Angle with the arch of aorta: Measured on the left side, the branches BCT, LCCA \& LScA made an angle of $88.09^{\circ}, 46.2^{\circ} \& 50.88^{\circ}$ with the arch respectively.

Shin study reports the corresponding three angles to be $65.3^{\circ}, 46.9^{\circ} \& 63.8^{\circ}$ [2]. Zamir study reports the corresponding three angles to be $56.4^{\circ}, 58.4^{\circ} \& 66.5^{\circ}$ [20].
Present study has found the angle made by the BCT with the arch to be little on the higher side as compared with the other two studies. The angle made by the LCCA with the arch is similar in present and Shin study though both are lower than that of the Zamir study. The angle made by the LScA with the arch in present study is lower than that reported in the other two studies.

Range of deviation of the BCT from the MVP: In 10 $(28.5 \%)$ cadavers BCT was originating on the left side of the MVP deviating by the mean distance of $4.3( \pm 2.71) \mathrm{mm}$ with a range of $1-10 \mathrm{~mm}$. While in 2 $(5.7 \%)$ cadavers the BCT originated directly on the MVP, as shown in the figure 4.

Shin study reports right side deviation of the BCT from MVP by an average distance of $0.92 \mathrm{~mm}$. Thus the BCT is originating almost on the MVP and appears to be on MVP in the fluoroscopic images [2].

Knowledge of these deviations from the MVP and the lengths of these vessels will help in catheter insertion and manipulation in the arch and its branches. Alsaif has reported mean deviations of BCT from MVP to be $9.33 \mathrm{~mm} \mathrm{[10].} \mathrm{In} \mathrm{this} \mathrm{study} \mathrm{BCT} \mathrm{is} \mathrm{deviating} \mathrm{by}$ comparatively higher distance from the MVP. Skandalakis J E in, 'Embryology for surgeons', states that the BCT origin to the left of the MVP is important. This slight distal or abnormal medial origin of the BCT can lead to anterior tracheal compression which can be life threatening. This condition can be surgically corrected by either BCT reimplant or by BCT arteriopexy to the underside of the sternum [21].

Chronic compression in such condition can lead to tracheomalacia.In the present study fibrous ridge was found to be present between openings of the BCT and the LCCA in 18 cadavers (51.4\%) and between openings of the LCCA and the LScA in only 7 cadavers (20\%). These fibrous ridges may be responsible for a typical pattern of catheter movement observed during fluoroscopic imaging. [2] These ridges may act as a guide to the point of origin of the major branches from the arch.

\section{Variations}

Common trunk: BCT and LCCA originated as a common trunk in 3 cadavers $(8.58 \%)$. Beigelman study found this variation in $8 \%$ cases which is similar to the results of the present study [22]. Alsaif has reported 
common trunk in $25 \%$ of the cadavers which is quite high as compared to the present study [10].

Normally right horn of aortic sac develops in to the BCT while the left horn becomes part of the arch of aorta. The two corresponding $3^{\text {rd }}$ arch arteries become the CCAs. If the left horn of the aortic sac gets absorbed in the right horn then the LCCA may arise as a common trunk with BCT or it may be seen as a branch from the BCT [23].

Mean length of the common trunk in present study was found to be $9.33 \mathrm{~mm}$ as against $15 \mathrm{~mm}$ reported by the Alsaif study [10].

CT deviated to the left of the MVP by an average distance of $6.66 \mathrm{~mm}$. Alsaif study found this deviation to be $13.83 \mathrm{~mm}[10]$.

Mean outer diameter of the CT was found to be 18.39 $\mathrm{mm}$ while mean inner diameter was $16.85 \mathrm{~mm}$. Average outer diameter of the CT in Alsaif study was $30.33 \mathrm{~mm}$ which is about double the diameter found in the present study[10]. The CT originated at an average distance of $26 \mathrm{~mm}$ from the origin of the arch of the aorta.

According to Indumathi S. common trunk is more liable to cause tracheal compression as it always originates to the left of the MVP [16]. Rob and Smith operative surgery states that a common trunk giving origin to $\mathrm{BCT}$ and LCCA is a contraindication for the procedure of the BCT endarterectomy [24].

Left vertebral artery with an abnormal origin : In 1 $(2.85 \%)$ cadaver the LVA took origin from the arch directly between the origins of the LCCA and the LScA. This variation is reported to be up to $5 \%$ in the literature and our finding is within that range.

According to study by Dr. Ughade the possibility of this variation ranges from $1.6-7 \%$. In his own study he found the LVA coming from the arch in $5 \%$ of the cases [3]. Study by Alsaif found this variation in $5.55 \%$ of the cases [10].

Bhatiya K. reports higher, $13.95 \%$, incidence of anomalous LVA in South Australian population who were born in South Australia and not immigrants [25].

Ogengo G. A. in his study reports that when LVA is arising from the arch, it is proximal to the LScA in $28.6 \%$ and distal to the LScA in $71.4 \%$ [13].
Four parts of the LVA, from its origin on LScA to its termination as the basilar artery, develop from four different sources. The first part develops from the dorsal branch of the left $7^{\text {th }}$ intersegmental artery.

One of the possible reasons for its anomalous origin directly from the arch of aorta could be persistence of the left sixth or even higher intersegmental artery which normally disappears [3]. Other reason for such anomaly could be absorption and incorporation of the proximal part of the left $7^{\text {th }}$ intersegmental artery prior to its dorsal branch into the developing aortic arch [23].

According to Komiyama M the LVA of aortic origin is associated with a predilection for vertebral artery dissection in comparison to LVA of the subclavian artery origin [26].

LVA of the aortic origin alters the cerebral hemodynamics predisposing such individuals to cerebral disorders and atherosclerotic changes [3].

Its length ( $1^{\text {st }}$ part) was $8 \mathrm{~cm}$. It deviated to the left of the MVP by $29 \mathrm{~mm}$. Its outer diameter was $5.03 \mathrm{~mm}$ and inner diameter was $4.44 \mathrm{~mm}$.

Dr. Ughade reports the diameter of the vertebral artery to be $4.2 \mathrm{~mm}$ [3], while Alsaif found it to be $5.5 \mathrm{~mm}$ [10]. The diameter found in the present study is comparable to other studies and normal. The artery is not hypoplastic as the criterion for this according to the earlier studies is of diameter $<3.5 \mathrm{~mm}$ [3].

Even hypoplastic the artery has the smallest diameter as compared to the other branches of the arch. The LVA is thus obscured by the other larger branches of the arch making its preoperative detection more difficult. The LVA coming from the arch can be diagnosed in only $40 \%$ of the cases [3]. Shin study reports that the origin of LCCA from the common trunk and the origin of LVA from the arch directly, should be always considered as a possibility by the endovascular surgeons when these vessels are not visualized during surgery [2].

Aortogram may be necessary in these cases.

\section{Conclusion}

In the present study arch showed normal branching pattern in $88.57 \%$ and variant pattern in $11.43 \%$ cadavers. The BCT deviated from the mid vertebral 
plane (MVP) to the right by $6 \mathrm{~mm}$ in 23 cadavers, to the left by $4.3 \mathrm{~mm}$ in 10 cadavers and was on MVP in 2 . The BCT originating on the left of the MVP is significant as it can lead to the tracheal compression.

The inner diameters of these branches and the angles at which they originate from the arch will be of value during the instrumentation or catheterization of these vessels and also for selection of instruments prior to surgery. The LVA of the aortic origin is of significance as it is more prone for arterial dissection and alters the cerebral hemodynamics increasing the risk of cerebral disorders.

Cadaveric study gives better three dimensional understanding of these vessels. The knowledge thus gained will be useful to the cardiologists, cardiothoracic surgeons and radiologists in various diagnostic and therapeutic procedures.

Funding: Nil, Conflict of interest: None

Permission of Ethical committee: Yes

\section{Abbreviations}

3DCT - 3 Dimentional Computerized Tomography, BCT - Brachiocephalic Trunk, LCCA - Left Common Carotid Artery, LScA- Left Subclavian Artery, MVP Mid Vertebral Plane, CT - Common Trunk, LVA Left Vertebral Artery, CAS - Carotid Artery Stenting

\section{References}

1. Moore KL, Dalley AF, Agur AMR. Clinically oriented anatomy. $6^{\text {th }}$ ed. New Delhi: Wolters Kluwer Health / Lippincott Williams and Wilkins; 2010.p.174.

2. Shin Y, Chung Y, Shin WH, Im SB, Hwang SC, Kim BT. A morphometric study on cadaveric aortic arch and its major branches in 25 Korean adults: The perspective of endovascular surgery. J Korean Neurosurg Soc 2008 August; 44(2): 78-83.

3. Ughade JM, Kardile PB, Ughade MN, Chaware PN, Pandit SV. Anomalous arch of aorta giving rise to left vertebral artery. Int J Biol Res 2012;3(4):2452-54.

4. Shivkumar GL, Pamidi N, Somayaji SN, Nayak S,Vollala VR. Anomalous branching pattern of the aortic arch and its clinical applications.Singapore medical J 2010;51(11):el182-3.
5. Romanes GJ. Cunningham's manual of practical anatomy. $15^{\text {th }}$ ed. Oxford: Oxford university press; 1993.p.14-15,18,57. (thorax and abdomen; vol 2)

6. Romanes GJ. Cunningham's manual of practical anatomy. $15^{\text {th }}$ ed. Oxford: Oxford university press; 1993.p.24-5,40.( Head neck and brain; vol 3)

7. Grant. Grant's dissector. $14^{\text {th }}$ ed. New Delhi; Wolter Kluwer (India) pvt 1td;2009.p.73-4.

8. Dagenais F. Anatomy of thoracic aorta and of its branches.Thorac Surg Clin 2011 May; 21(2): 219-27, viii.

9. Bannister HL, Berry MM, Collins P, Dyson M, Dussek JE, Ferguson MWJ. Gray's anatomy. $38^{\text {th }}$ ed. London: Churchill Livingstone; 1995. p1510-11,13-14.

10. Haifa AA, Ramadan WS. An anatomical study of the aortic arch variations. JKAU:Med Sci 2010;17(2):37-54.

11. Adachi B.Das arterian system der Japaner. Kyoto : Verlag der kieserlich-Japaniscen universitat 1928:29-41

12. Anson BJ, Mcvay CB. Surgical anatomy. $5^{\text {th }}$ ed. Philadelphia ,London, Toronto: W.B.Saunders; 1971.p. 408-12.

13. Ogengo'o JA, Olabu BO, Gatonga PM, Munguti JK. Branching pattern of aortic arch in a Kenyan population. J Morphol sci 2010;27(2):51-55.

14. Rekha P, Senthilkumar S. A study on branching pattern of human aortic arch and its variations in south indian population. J Morphol sci 2013;30(1):11-15.

15. Wiiliams GD, Edmonds HW. Variations in the arrangement of the branches arising from the aortic arch in American whites and negroes. Anat rec 1935;62:13946.

16. Indumathi S, Sudha S, Rajila HSR. Aortic arch and variations in its branching pattern. Journal of clin and diagnostic research 2010 oct;4:3134-43.

17. Faggioli GL, Ferry M, Freyrie A, Garguilo M, Fratesi F, Rossi C et al. Aortic arch anomalies are associated with increased risk of neurological events in carotid stent procedures. Eur J Vasc Endovasc Surg 2007 Apr; 33(4): 436-41. 
18. Wiedemann D, Kocher A, Mahr S, Longato S, Bonaros N, Schachner T. Extraordinary branching pattern of the aortic arch. Clinical anatomy 2013 jan 27;

19. Ogawa T, Okudera T,Kyo N, Sasaki N, Inugami A, Uemura K et al. Cerebral aneurysms: Evaluation with 3 dimentional CT angiography. AJNR Am J Neuroradiol 1996 March; 17: 447-54.

20. Zamir M, Sinclair P. Origin of the brachiocephalic trunk, left carotid and left subclavian arteries from the arch of the human aorta.Invest radiol 1991;26:128-33.

21. Skandalakis JE, Gray SW.Embryology for surgeons The embryological basis for the treatment of congenital anomalies. $2^{\text {nd }}$ ed. Baltimore,Maryland,USA: Wiliam's and Wilkins; 1994.p. 988-91.
22. Beigelman C, Mourey-Gerosa I, Gamsu G, Grenier P. new morphologic approach to the classification of anomalies of the aortic arch. Eur radiol 1995;5:435-42.

23. Manyama M, Rambau P, Gilyoma J, Mahalu W. A variant branching pattern of the aortic arch: a case report. J of cardiothoracic surg 2011;6:29.

24. Jamieson CW, Yao JST.Rob and Smiths' operative surgery, vascular surgery. $5^{\text {th }}$ ed.London: Chapman and Hall, 2-6 Boundary row, London; 1994.p.141.

25. Bhatia K, Gabriel MN, Henneberg M. anatomical variations in the branches of the human aortic arch: a recent study of a south Australian population. Folia morphol (wartz) 2005 aug ;64(3):217-23.

26. Komiyama M, Morikawa $\mathrm{T}$, Nakajima $\mathrm{H}$, Nishikawa M, Yasui T. High incidence of arterial dissection associated with left vertebral artery of aortic origin. Neurol med chir (Tokyo) 2001;41:8-12.

\section{How to cite this article?}

Junagade B, Mukherjee A. The Morphometric study of the normal and variant branching pattern of the Aortic arch by cadaveric dissection. Int J Med Res Rev 2015;3(5):461-469. doi: 10.17511/ijmrr.2015.i5.090. 